\title{
Can the Severity of Dependence Scale Be Usefully Applied to 'Ecstasy'?
}

\author{
Raimondo Bruno ${ }^{\mathrm{a}}$ Allison J. Matthews ${ }^{\mathrm{a}}$ Libby Topp ${ }^{\mathrm{b}}$ Louisa Degenhardt ${ }^{\mathrm{c}}$ \\ Rapson Gomez ${ }^{\mathrm{a}}$ Matthew Dunn ${ }^{\mathrm{c}}$ \\ ${ }^{a}$ School of Psychology, University of Tasmania, Hobart, Tas., ${ }^{b}$ Centre for Health Research in Criminal Justice, \\ Justice Health, Pagewood, N.S.W., and ' National Drug and Alcohol Research Centre, University of New South Wales, \\ Sydney, N.S.W., Australia
}

\section{Key Words}

Methylenedioxymethamphetamine - Drug dependency •

Screening tests $\cdot$ Severity of Dependence Scale $\cdot$ Factor

structure

\begin{abstract}
Background/Aims: Although use of 'ecstasy' (drugs sold as containing 3,4-methylenedioxymethamphetamine) is prevalent, it is typically infrequent, and treatment presentations involving ecstasy as a principal problem drug are relatively rare. Human case reports and animal literature suggest dependence potential, although there may be some unique aspects to this syndrome for ecstasy in comparison to other substances. The Severity of Dependence Scale (SDS) was examined to determine whether this could usefully identify 'dependent' ecstasy consumers. Methods: We conducted a cross-sectional survey of 1,658 frequent (at least monthly) ecstasy consumers across Australia, assessing drug use, associated harms and risk behaviours. Dependence was evaluated with the SDS, using a cut-off of $\geq 4$ to identify potential 'dependence'. Results: One fifth of the participants were screened as potentially dependent. These individuals used ecstasy more frequently, in greater amounts, engaged more extensively in risk behaviours and reported greater role interference than other participants. These findings were independent of methamphetamine use or dependence. The underlying structure of the ecstasy SDS was bifactorial. Con-
\end{abstract}

clusions: The SDS has demonstrated construct validity as a screening tool to identify ecstasy users at elevated risk of experiencing adverse consequences, including features of dependence. The underlying structure of dependence symptoms differs for ecstasy compared to other drug classes, and some dependent consumers use the drug infrequently. The unique neurotoxic potential and entactogenic effects of ecstasy may require a distinct nosological classification for the experience of dependence associated with the drug.

Copyright $\odot 2009$ S. Karger AG, Basel

\section{Introduction}

Globally, the use of 'ecstasy' (drugs sold as containing 3,4-methylenedioxymethamphetamine, MDMA) dramatically increased during the 1990s [1]. Whereas substantial research has examined the association between ecstasy and cognitive function $[2,3]$ and affective disorders $[4,5]$, few studies have considered the experience of dependence associated with ecstasy [6-14]. This bias may reflect an early view that dependence was unlikely $[15,16]$ and findings that even heavy users typically consume the drug weekly or less frequently $[17,18]$, a usage pattern inconsistent with traditional notions of 'dependence'.

Many frequent ecstasy consumers report few adverse health or social consequences from use $[19,20]$, but there

\section{KARGER \\ Fax +4161306 1234 \\ E-Mail karger@karger.ch}

www.karger.com
(C) 2009 S. Karger AG, Basel

0302-282X/09/0604-0137\$26.00/0

Accessible online at:

www.karger.com/nps
Raimondo Bruno

School of Psychology, University of Tasmania

Private Bag 30

Hobart, Tas. 7001 (Australia)

Tel. +61 36226 2240, Fax +61 36226 2883, E-Mail Raimondo.Bruno@utas.edu.au 
are exceptions. Treatment presentations involving ecstasy as a principal problem drug are relatively uncommon but nonetheless occur [21-23], and ecstasy commonly features in recent drug histories of 'club drug' users seeking treatment $[24,25]$.

The dependence potential of MDMA has been examined using animal models. The drug is rewarding, with self-administration apparent $[26,27]$, and is reinforcing in both classical and operant conditioning paradigms [28-30]. MDMA increases the dopaminergic activity in the mesolimbic 'reward' pathway, a key circuit in addiction neurobiology [31-33]. However, MDMA does not maintain behaviour as well as cocaine or methamphetamine [34, 35], and mesolimbic dopaminergic release is attenuated by antagonistic MDMA-induced serotonergic activity [31], both suggesting weaker reinforcing effects of MDMA relative to other drugs of dependence. Models of 'withdrawal', derived from acute serotonin antagonism in chronically MDMA-maintained animals, produce relatively minor physical signs, and dysphoric (conditioned aversion) responses are absent [28]. Vulnerability to relapse is apparent, however, with reinstatement of previously extinguished conditioned place preference following MDMA re-exposure [29]. Together, animal literature suggests dependence potential for MDMA, but that this is relatively attenuated and displays some unique characteristics compared to other drugs.

Among humans, each of the Diagnostic and Statistical Manual of Mental Disorders (DSM) dependence criteria has been reported in relation to ecstasy $[6-8,11-13]$. However, consistent with animal literature, some symptoms manifest themselves in distinct ways. Tolerance to ecstasy is common and has been comprehensively reviewed [36]. However, as the use is typically intermittent and low dose, neuroadaptation alone may not account for the degree of tolerance experienced, and ecstasy-induced serotonergic system damage may exacerbate this effect [36]. The definition of ecstasy 'withdrawal' is complicated by the fact that, like other stimulants, the period following acute use is marked by multiple phases: an initial dysphoric 'crash' in response to central nervous system over-stimulation, followed, in chronic consumers, by an extended 'withdrawal' phase, as a reflection of neurophysiological adaptation, marked by anhedonia and anergia, more relevant to the concept of dependence [37]. Question probes in existing standardised diagnostic interviews do not clearly differentiate these phases, leading to almost universal nomination of this symptom among regular consumers in some studies [6]. For example, the withdrawal syndrome probe item 'During the first few hours or days of not using ecstasy ... did you ever feel tired, sleepy or weak' was nominated by approximately half of a sample of infrequent consumers [8] but also a similar proportion of individuals after their first occasion of use [19], the latter clearly reflecting sub-acute effects of the drug rather than neuroadaptation. Such symptoms of 'withdrawal' have demonstrated poor test-retest reliability [8]. Moreover, the precise symptoms expected during 'withdrawal' are similarly ill defined, with some studies using open-ended probes [6] and others prompting for withdrawal signs from every substance category [8]. The rates of the symptom 'continued use despite knowledge of physical or psychological problems' differ dramatically across studies: present among $28 \%$ [95\% confidence interval $(\mathrm{CI})=22-35]$ of a sample of at least 3-monthly consumers [6], in contrast to $63 \%(95 \%=$ CI $44-87)$ of a sample reporting less frequent use [8]. Given the distinct short- $[38]$ and long-term $[3,5]$ psychological sequelae of ecstasy, reflecting transient and sustained reductions in functional serotonin respectively [39], this item may require more precise definition. For example, reversible low mood and memory in the days following ecstasy use have been demonstrated in novice users [40] and may reflect short-term reversible changes in serotonin availability [39]. While this is clearly a 'psychological problem' following ecstasy use, it is a matter of debate whether a decision to use the drug again after such a reversible change is reflective of the intended meaning of this dependence symptom item, namely, loss of control over drug use [41]. Although some research groups have made impressive advances in the assessment of these symptoms [12], the notable between-study variability for rates of endorsement of 'withdrawal' and 'continued use despite knowledge of harm' items in particular $[6,8,11]$ demonstrate the need for better discrimination of short- versus longterm effects of use in standardised item definitions in order to minimise the measurement error apparent in current assessments of dependence. Notwithstanding these definitional complexities, however, case reports of unambiguous full ecstasy dependence syndromes have been reported [7].

Despite the lack of clarity on several symptoms, an ecstasy dependence syndrome can be coded in DSM-IV as either hallucinogen dependence (304.50) or, given the inclusion of 'all substances with a substituted phenylethylamine structure' [42, p. 223] in this category, amphetamine dependence (304.40). While this may be appropriate considering the common adulteration of ecstasy tablets with methamphetamine [43], it is problematic given the differing features of dependence for these classes. 
Amphetamine dependence includes a withdrawal syndrome, and its DSM-IV dependence criteria are unifactorial [44], consistent with findings for alcohol, opioids and cocaine [45]. Hallucinogen dependence does not include a withdrawal syndrome, and its DSM-IV diagnostic criteria are not unifactorial [46]. A unifactorial structure of dependence symptoms implies that the behavioural syndrome reflects a single underlying biological mechanism [47], likely mirroring functional changes in an integrated neurobiological circuit affected by chronic drug use [48].

There is debate about the categorisation of ecstasy dependence in future DSM revisions $[8,49]$. The single study to examine the structure of DSM dependence criteria for ecstasy [6] identified a bifactorial structure, consistent with findings for hallucinogens [46]. Independent components were defined as 'compulsive use' (use despite problems, giving up important activities, unsuccessful attempts to stop, withdrawal and excessive time spent obtaining or using) and 'escalating use' (tolerance and using more or for longer than intended). Despite the lack of a unified dependence syndrome [50], and a relatively low frequency of ecstasy use among those classified 'dependent', these criteria did define a sub-group of consumers who experienced greater adverse physical, psychological, financial and social consequences from their use.

The Severity of Dependence Scale (SDS) is a brief scale assessing the psychological component of dependence, namely, compulsion to use. It addresses feelings of impaired control over, preoccupation with and anxieties about drug taking [51]. Importantly for the investigation of ecstasy dependence, this scale avoids symptoms with currently controversial definitions ('withdrawal', 'use despite problems') which may artificially inflate dependence prevalence. Moreover, given that animal literature suggests that the biological basis of dependence for ecstasy is weaker than for other drugs, it may be more appropriate to focus on psychological components. The SDS has strong psychometric properties [51, 52]. Importantly, the SDS is unidimensional for opioids, amphetamine and cocaine [51], and has high diagnostic utility in detecting DSM dependence for cocaine, amphetamine, cannabis and benzodiazepines [53-56].

The characteristics of the SDS in regard to ecstasy have not been studied. The current study aimed:

(1) to examine the characteristics of the SDS in regard to ecstasy;

(2) to investigate the construct validity of the SDS in terms of whether those considered dependent on the scale also engage in behaviours consistent with this classifi- cation, such as higher levels of use and risk behaviours, and experience a greater degree of adverse consequences from their use, and

(3) given the extent of poly-drug use among ecstasy consumers [57], to determine whether identification of any such ecstasy-dependent group provides useful predictive information beyond that provided by already validated syndromes, such as methamphetamine dependence.

\section{Method}

Participants and Procedure

Interviews were conducted as part of the Ecstasy and Related Drugs Reporting System, a surveillance system for the ecstasy market [58]. A total of 1,658 participants were recruited through a purposive sampling strategy from each Australian capital city in 2004 and 2005. The inclusion criteria required that participants be at least 16 years of age and had used 'ecstasy' at least once monthly in the preceding 6 months. Trained interviewers conducted one-on-one, face-to-face interviews with the participants lasting 30-60 min in a range of public locations. Demographic characteristics, drug use, criminal activity, drug-related problems, and sexual and injecting risk behaviours were assessed. Symptoms of dependence for ecstasy and, independently, methamphetamine were evaluated using the SDS (items detailed in fig. 1 and [51]). The respondents provided written informed consent and were reimbursed AUD 30. Ethical approval was obtained from jurisdictional ethics committees. Full methodological detail and findings are available elsewhere $[59,60]$.

\section{Analyses}

Using SPSS 14.0.2, continuous variables were analysed with ANOVA; the $\chi^{2}$ test and odds ratios (OR) with 95\% CI derived from independent logistic regression models were used to examine categorical variables. Mplus 4.1 was applied to conduct confirmatory factor-analytic models, with the mean and varianceadjusted weighted least squares extraction procedure used for estimation, as this is appropriate for skewed data. Statistical fit was ascertained using the mean and variance-adjusted weighted least squares fit function $\chi^{2}$, which assesses closeness of fit between the unrestricted sample covariance matrix and the restricted (model) covariance matrix, taking into consideration non-normality in the data. As $\chi^{2}$ values are inflated by large sample sizes, model fit indices of root mean squared error of approximation (RMSEA [61]) and the comparative fit index (CFI [62]) were also examined. Despite recent controversy [63-65], RMSEA values $<0.06$ and CFI values $>0.95$ are considered to indicate good fit [66-68].

\section{Results}

\section{Demographics}

The mean participant age was 24 years $(\mathrm{SD}=6$, range $=$ $16-61)$, and $60 \%(95 \% \mathrm{CI}=58-62)$ were male. Almost 3 


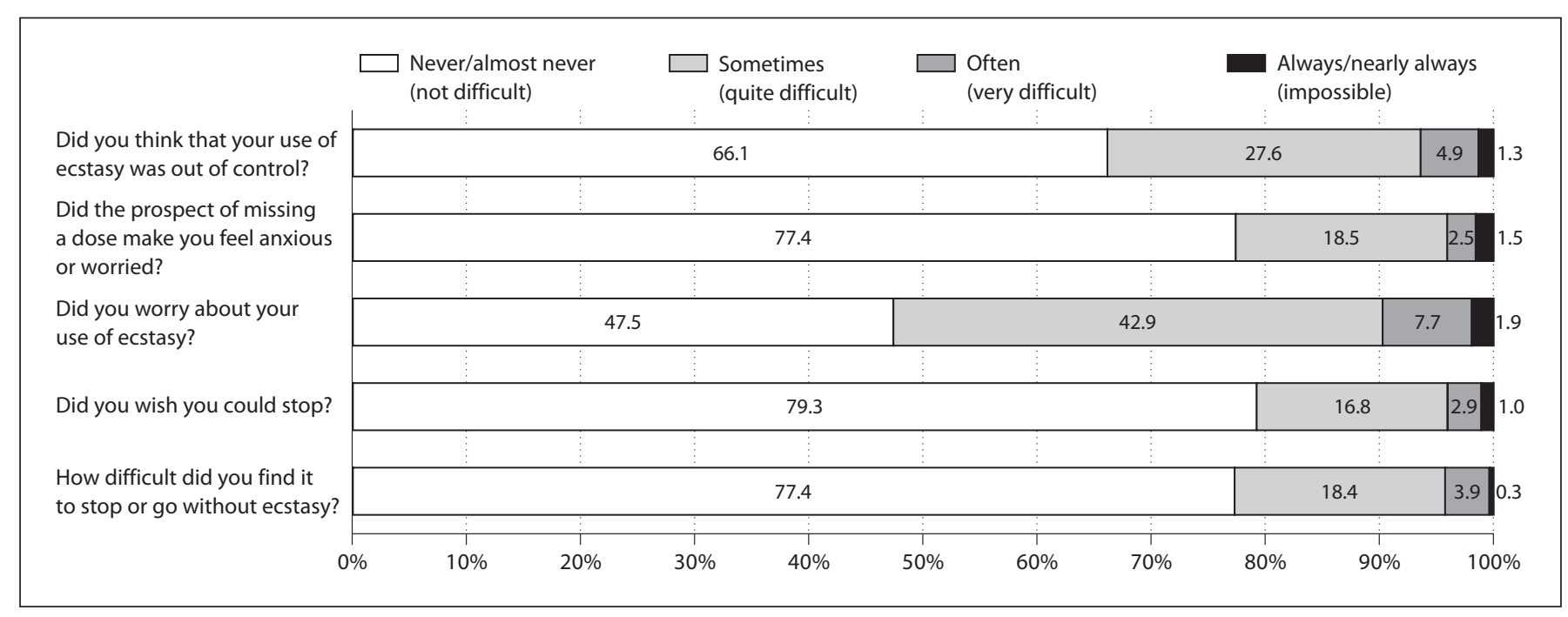

Fig. 1. Distribution of responses to the individual items of the SDS for ecstasy. Anchor points for the last item are listed in parentheses in the figure legend.

quarters $(72 \%, 95 \% \mathrm{CI}=70-74)$ had completed secondary education, $27 \%(95 \% \mathrm{CI}=25-30)$ also held trade or technical qualifications, and $23 \%(95 \% \mathrm{CI}=21-25)$ possessed university degrees. The majority were currently employed $(61 \%, 95 \% \mathrm{CI}=59-64)$ or studying $(23 \%, 95 \% \mathrm{CI}=21-25)$. Just 3\% (95\% CI $=2-4)$ were currently undertaking drug treatment. The participants had used ecstasy on a mean of 21 days of the past $180(\mathrm{SD}=15$, range $=5-180)$, or approximately weekly, and typically swallowed the drug $(93 \%, 95 \%$ CI $=91-94)$.

\section{SDS for Ecstasy}

One third of the sample $(34 \%, 95 \% \mathrm{CI}=32-37)$ did not endorse any SDS dependence symptom. A further $21 \%$ $(95 \% \mathrm{CI}=19-23)$ nominated the lowest level of concern ('sometimes') for a single item. The most commonly nominated item was being 'sometimes' worried about use of ecstasy $(43 \%, 95 \% \mathrm{CI}=41-45)$, with two-thirds of the participants or more reporting no problems or concerns on other SDS items (fig. 1). Just 15\% (95\% CI $=14-17)$ nominated more than the lowest level of concern ('often') 'very difficult' or 'nearly always'/'impossible') for any one item. In the absence of an empirically defined cut-off value on the SDS to identify ecstasy dependence, the validated cut-off for methamphetamine dependence (total SDS $\geq 4$ [54]) was applied. Eighteen percent (95\% CI = 16-20) reported an SDS score of $\geq 4$ and are subsequently classified as ecstasy dependent.
Variables Associated with Ecstasy Dependence

Independent logistic regression models show those classified dependent were significantly more likely than non-dependent participants to be: participating in drug treatment $(\mathrm{OR}=2.74)$ and female $(\mathrm{OR}=1.31)$, and less likely to have completed a year 12 education $(\mathrm{OR}=1.62$, table 1). There were no differences in age or unemployment rates between the groups.

Compared to non-dependent participants, those classified dependent had used ecstasy on a greater number of days in the preceding 6 months (29 vs. 19 days, F(1, $1656)=88.0$, MSE $=276.3, \mathrm{p}<0.001)$. Dependent respondents were significantly more likely to have used ecstasy weekly or more often $(\mathrm{OR}=3.13)$, to usually consume $\geq 2$ tablets in a session $(\mathrm{OR}=1.91)$ and to have 'binged' (used stimulants for $\geq 48 \mathrm{~h}$ without sleep; $\mathrm{OR}=1.66$, table 1 ). Age of onset, route of administration and duration of ecstasy use did not differ between the groups. Few differences in other drug use were observed, although those classified as dependent were more likely to have recently used methamphetamine $(\mathrm{OR}=1.52)$ weekly or more often.

Although recent harms attributed to ecstasy among our sample were infrequent, these were consistently elevated among dependent respondents (table 2), more than a third of whom reported recent ecstasy-related social, financial or work-related problems $(\mathrm{OR}=3.17,2.36$ and 1.99 respectively). Approximately 1 in 10 dependent participants had recently sought assistance from health ser- 
Table 1. Demographic characteristics and patterns of ecstasy and other drug use according to SDS groupings

\begin{tabular}{|c|c|c|c|c|}
\hline & \multirow{2}{*}{$\begin{array}{l}\text { Not dependent } \\
(\mathrm{n}=1,356), \%\end{array}$} & \multicolumn{3}{|c|}{ Dependent $(e S D S \geq 4)(n=302)$} \\
\hline & & $\%$ & OR & $95 \%$ CI \\
\hline \multicolumn{5}{|l|}{ Demographic characteristics } \\
\hline Female & 38.7 & 45.4 & $1.31^{*}$ & $1.02-1.69$ \\
\hline Aged $\leq 22$ years $^{\mathrm{a}}$ & 49.9 & 55.8 & 1.27 & $0.99-1.63$ \\
\hline Did not complete year 12 (and not currently studying) & 23.8 & 33.6 & $1.62^{* * *}$ & $1.24-2.12^{\mathrm{b}}$ \\
\hline Unemployed & 15.1 & 18.3 & 1.26 & $0.91-1.75$ \\
\hline Currently in drug treatment & 2.3 & 6.0 & $2.74^{* * *}$ & $1.50-4.92^{\mathrm{b}}$ \\
\hline \multicolumn{5}{|l|}{ Patterns of Ecstasy use } \\
\hline First used ecstasy $\leq 16$ years & 20.7 & 23.2 & 1.15 & $0.86-1.56$ \\
\hline Used ecstasy for $\geq 5$ years & 42.7 & 40.5 & 0.91 & $0.71-1.18$ \\
\hline Used ecstasy $\geq$ weekly in past 6 months & 30.8 & 58.3 & $3.13^{* * *}$ & $2.42-4.05^{\mathrm{b}}$ \\
\hline Usually consume $\geq 2$ tablets when take ecstasy & 57.9 & 72.5 & $1.91^{* * *}$ & $1.45-2.53^{\mathrm{b}}$ \\
\hline Usually administer ecstasy by snorting, anal/vaginal or IV in last 6 months & 7.4 & 9.9 & 1.37 & $0.89-2.10$ \\
\hline Recent binge use of stimulants (under influence for $\geq 48 \mathrm{~h}$ without sleep) & 43.5 & 56.2 & $1.66^{* * *}$ & $1.29-2.14$ \\
\hline \multicolumn{5}{|l|}{ Other drug use in last 6 months } \\
\hline Used alcohol & 95.9 & 97.0 & 1.40 & $0.69-2.85$ \\
\hline Used alcohol $\geq$ weekly & 77.0 & 74.5 & 0.87 & $0.66-1.17$ \\
\hline Usually binge drink (consume $\geq 5$ standard drinks) when taking ecstasy & 70.3 & 75.0 & 1.26 & $0.98-1.79$ \\
\hline Used cannabis & 82.5 & 83.7 & 1.09 & $0.78-1.53$ \\
\hline Used cannabis $\geq$ weekly & 51.3 & 51.0 & 0.99 & $0.77-1.27$ \\
\hline Used methamphetamine & 82.9 & 84.1 & 1.09 & $0.78-1.53$ \\
\hline Used methamphetamine $\geq$ weekly & 22.1 & 30.1 & $1.52^{* *}$ & $1.15-2.00$ \\
\hline Used cocaine & 33.2 & 36.4 & 1.15 & $0.89-1.50$ \\
\hline Used $\gamma$-hydroxybutyrate $/ \gamma$-butyrolactone & 5.0 & 7.6 & 1.56 & $0.96-2.55$ \\
\hline Used LSD & 28.6 & 28.8 & 1.01 & $0.77-1.33$ \\
\hline Injected any drug & 11.2 & 11.4 & 1.03 & $0.69-1.52$ \\
\hline
\end{tabular}

\footnotetext{
${ }^{a}$ Based on median split for the sample.

${ }^{\mathrm{b}}$ Remains significant after those classified as methamphetamine dependent are excluded: $\mathrm{n}=1,141$ for not ecstasy-dependent and $\mathrm{n}=204$ for ecstasy-dependent groups, respectively.

${ }^{*} \mathrm{p}<0.05 ;{ }^{* *} \mathrm{p}<0.01 ;{ }^{* * *} \mathrm{p}<0.001$.
}

vices (e.g. first aid, hospital, medical practitioner) or talkbased therapies (e.g. drug counsellor, psychologist) regarding their ecstasy use, at significantly higher rates than their non-dependent counterparts $(\mathrm{OR}=3.10$ and 7.19 respectively). 'Overdoses' (e.g. tremors, anxiety, hyperthermia) attributed to ecstasy were uncommon but were twice as likely in dependent (6\%) as non-dependent participants $(\mathrm{OR}=2.19)$. Compared to non-dependent participants, those classified dependent were significantly more likely to have recently engaged in unprotected penetrative sex with a casual partner $(\mathrm{OR}=1.43)$, property crime $(\mathrm{OR}=1.99)$ and/or drug dealing $(\mathrm{OR}=1.48)$.

One third of the ecstasy-dependent participants were also classified methamphetamine dependent (fig. 2) using established SDS cut-off values [54], a rate higher than among those not ecstasy dependent $(\mathrm{OR}=2.78)$. Notably, however, those classified ecstasy dependent were no more likely to have experienced recent social, financial, legal or work problems attributed to methamphetamine, nor to have accessed talk-based therapies or experienced 'overdose' attributed to methamphetamine. While uncommon, those classified ecstasy dependent were more likely than non-dependent participants to have recently sought assistance from health services due to methamphetamine use $(5 \%, \mathrm{OR}=2.57)$.

\section{Independence of Ecstasy and Methamphetamine \\ Dependence Syndromes}

Given the elevated rates of methamphetamine dependence among those classified ecstasy dependent, the relationships between these syndromes were examined further. While the majority of the sample were not identified 
Table 2. Risk behaviours and experience of harms according to SDS groupings

Not dependent Dependent $(\mathrm{eSDS} \geq 4)(\mathrm{n}=302)$

$(\mathrm{n}=1,356), \%$

$\%$

OR

$95 \% \mathrm{CI}$

Harms attributed to Ecstasy in past 6 months

Experienced social problems

Experienced financial problems

Experienced legal problems

Experienced work problems

'Overdose' attributed to ecstasy ${ }^{\mathrm{b}}$

Accessed health services (first aid, ambulance, emergency department,

hospital or general practitioner) due to ecstasy use

Accessed talk therapy (counsellor, alcohol and drug worker, social worker, psychologist or psychiatrist) due to ecstasy

Harms attributed to methamphetamine use in last 6 months

Dependent on methamphetamine (SDS $\geq 4$ )

Experienced social problems

Experienced financial problems

Experienced legal problems

Experienced work problems

'Overdose' attributed to methamphetamine ${ }^{\mathrm{b}}$

Accessed a health service (first aid, ambulance, emergency department,

hospital or general practitioner) due to methamphetamine use

Accessed talk therapy (counsellor, alcohol and drug worker, social worker, psychologist or psychiatrist) due to methamphetamine use

Risky sexual behaviours

Had unsafe sex with casual partner in past 6 months

$\begin{array}{rrll}14.7 & 35.4 & 3.17^{* * *} & 2.40-4.19^{\mathrm{a}} \\ 16.9 & 32.5 & 2.36^{* * *} & 1.78-3.13^{\mathrm{a}} \\ 1.8 & 3.0 & 1.71 & 0.78-3.71 \\ 20.6 & 34.1 & 1.99^{* * *} & 1.52-2.61^{\mathrm{a}} \\ 2.7 & 5.6 & 2.19^{* *} & 1.21-3.95\end{array}$

Crime

Arrested in the past 12 months

Committed property crime in the past month

Drug dealing for cash profit in the past month

Committed fraud in the past month

Committed violent crime in the past month

\section{3}

1.4

\section{3}

8.8

6.6

1.3

7.1

0.8

2.0

2.4

22.6

29.5

31.8

11.3

9.6

1.7

\section{6}

\section{7}

5.0

1.7

0.68

$3.10^{* * *}$

$1.91-5.02^{\mathrm{a}}$

$7.19^{* * *} \quad 3.96-13.06^{\mathrm{a}}$

\begin{tabular}{ll}
$2.78^{* * *}$ & $2.09-3.71$ \\
1.31 & $0.87-1.96$ \\
1.51 & $0.97-2.35$ \\
1.25 & $0.46-3.40$ \\
0.93 & $0.57-1.53$ \\
2.06 & $0.71-5.70$ \\
$2.57^{* *}$ & $1.35-4.90$ \\
& \\
0.68 & $0.26-1.74$ \\
\hline
\end{tabular}

9.7

$\begin{array}{rrll}9.7 & 11.6 & 1.22 & 0.82-1.82 \\ 4.9 & 9.3 & 1.99^{* *} & 1.26-3.16^{\mathrm{a}} \\ 18.5 & 25.2 & 1.48^{* *} & 1.11-1.99 \\ 2.3 & 3.0 & 1.31 & 0.62-2.78 \\ 1.9 & 2.0 & 1.04 & 0.42-2.54\end{array}$

${ }^{a}$ Remains significant after those classified as methamphetamine dependent are excluded: $\mathrm{n}=1,141$ for not ecstasy-dependent and $\mathrm{n}=204$ for ecstasy-dependent groups, respectively.

b 'Overdose' was defined as experience of symptoms including: nausea, vomiting, chest pain, tremors, markedly increased body temperature, delirium, significant paranoia, panic or anxiety.

${ }^{*} \mathrm{p}<0.05 ;{ }^{* *} \mathrm{p}<0.01 ;{ }^{* * *} \mathrm{p}<0.001$.

as dependent on either drug $(70 \%, 95 \% \mathrm{CI}=68-72)$, similar proportions were identified as possibly methamphetamine $(18 \%, 95 \% \mathrm{CI}=16-19)$ or ecstasy $(18 \%, 95 \% \mathrm{CI}=$ 17-20) dependent (fig. 2). However, there was substantial distinction between these groups: despite regularly using ecstasy, $67 \%$ (95\% CI = 61-72) of those identified as methamphetamine dependent were not ecstasy dependent, and $68 \%$ (95\% CI $=63-74)$ of those classified ecstasy dependent were not methamphetamine dependent. Moreover, a substantial proportion $(16 \%, 95 \% \mathrm{CI}=12-20)$ had not used methamphetamine at all in the preceding 6 months.
To examine the independence of the effect of ecstasy dependence, all regression analyses were replicated excluding methamphetamine-dependent respondents. Ecstasy-dependent participants remained significantly more likely than non-dependent ones to use ecstasy weekly or more often, to take $\geq 2$ tablets in a session, to have recently experienced social, financial or legal problems attributed to ecstasy use, recently engaged in property crime, to have accessed health- or talk-based therapies for ecstasy-related problems, to be undertaking drug treatment, to have had unprotected penetrative sex with 


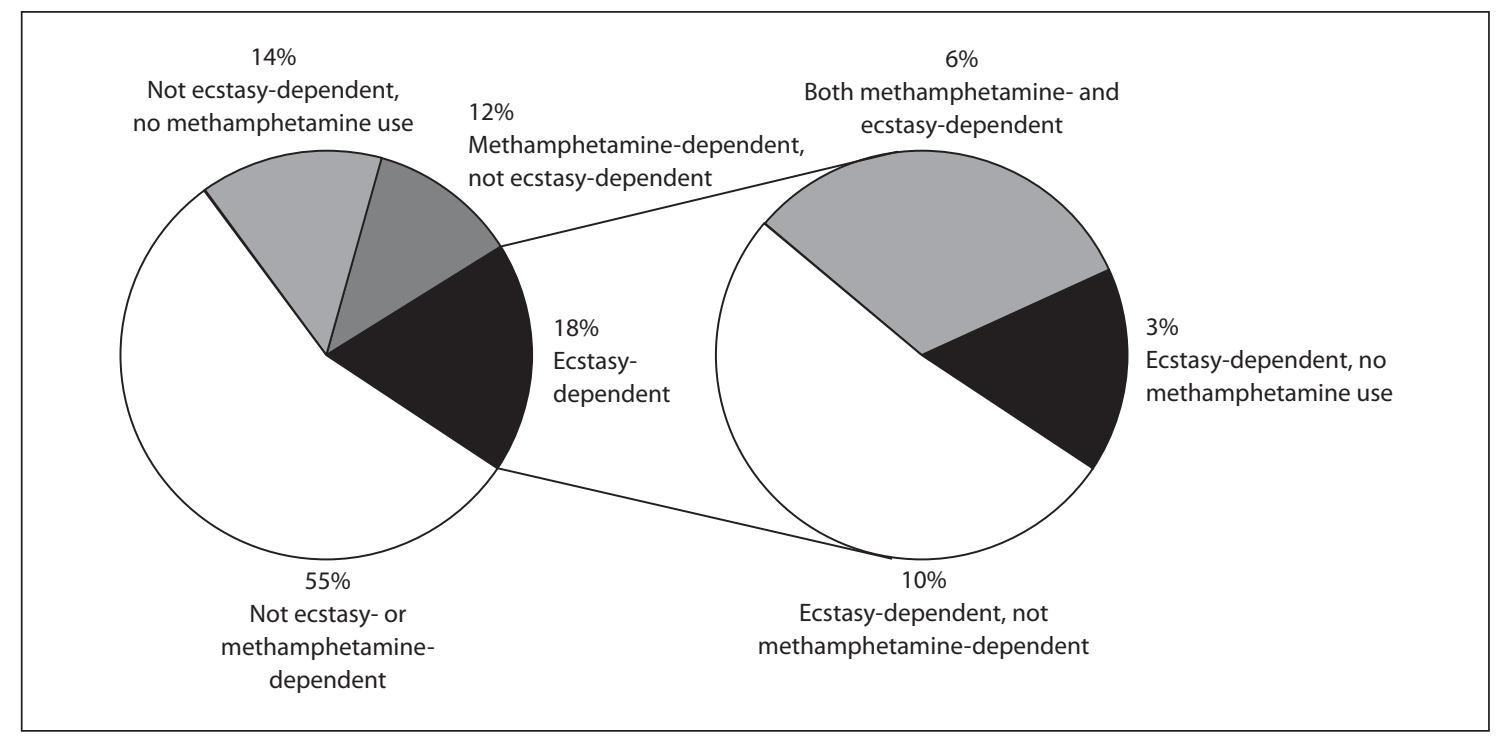

Fig. 2. Proportions of the cohort possibly experiencing ecstasy or methamphetamine dependence, based on SDS cut-off scores of $\geq 4$ (as per Topp and Mattick [54]).

a casual partner, and/or to have completed fewer years of schooling (tables 1,2).

Secondly, a sequential multinomial logistic regression analysis was conducted on the full dataset, with methamphetamine dependence forced into the regression analysis, and variables identified as bivariately associated with ecstasy dependence in tables 1 and 2 subsequently examined in a stepwise fashion. In this way, the association of these variables with ecstasy dependence additional to that of methamphetamine dependence (and each other) could be examined. With the exception of drug treatment, risky sexual behaviour and property crime, all the variables noted to be independently associated with ecstasy dependence remained significant in the sequential multinomial model.

\section{Structure of the SDS for Ecstasy}

An earlier study on a partially independent sample [69] identified a bifactorial structure for the SDS for ecstasy using exploratory factor analysis, with items concerning a desire to discontinue use, difficulties with this and anxiety about missing the drug forming one factor, with the second, correlated, factor combining items relating to concerns about the extent of use (worry and loss of control). These factors were similar to those identified in DSM-IV dependence criteria symptoms for ecstasy [6]. The degree of fit for unifactorial and this 2-factor model of SDS items were compared using confirmatory factor analysis.

The Severity of Dependence Scale for Ecstasy
The fit indices of the 1-factor model were $\chi^{2}(5)=75$, $\mathrm{p}<0.001$, RMSEA $=0.092$ and CFI $=0.97$. These were $\chi^{2}(4)=34, p<0.001$, RMSEA $=0.067$ and CFI $=0.99$ for the 2 -factor model. The $\chi^{2}$ were significant for both analyses, indicating no statistical support for the models. However, in terms of guidelines for fit indices [66], the CFI values indicated good fit in both models. The RMSEA data indicated poor fit for the 1-factor model; the 2 -factor model closely approached good fit criterion. Additional analysis indicated difference in statistical fit between the 1- and 2-factor models, $\Delta \chi^{2}(\Delta$ d.f. $=1)=34$, $\mathrm{p}<0.001$. Thus, although the 2 -factor model met CFI but not RMSEA criteria for adequate fit, it was a significantly better fit than the 1-factor model. So there was more support for the 2-factor model.

\section{Discussion}

There are two key findings from the current study. Firstly, the use of an SDS cut-off value of $\geq 4$ as indicative of possible ecstasy dependence demonstrated construct validity. This defined a group with behaviours reflective of dependence and at greater risk of experiencing adverse consequences associated with use. Secondly, consistent with findings for DSM-IV dependence items [6], the SDS for ecstasy does not retain the unifactorial structure identified for methamphetamine or opioids. This suggests 
that there may be something unique about the syndrome of dependence for this drug.

It is notable that the proportion of the current sample identified as potentially dependent - approximately 1 in 5 regular consumers - is remarkably consistent across studies of this group of drug users internationally, using the SDS $[6,17]$ as well as independent measures $[11,14]$ (though notably lower than studies applying detailed investigations of withdrawal symptoms $[8,12])$. Although participants classified as ecstasy dependent used methamphetamine more frequently and were at greater risk of methamphetamine dependence, multivariate analyses demonstrated that this was not sufficient to account for their elevated levels of drug-related harm. Moreover, consumers clearly distinguished the sequelae of ecstasy from those of methamphetamine. This demonstrates that the SDS applied to ecstasy can provide clinically relevant and unique information relating to problematic use of this drug.

Whereas an 'ecstasy dependence syndrome' is yet to be fully validated, our findings indicate that despite ecstasy not commonly being a principal drug of concern among treatment seekers $[21,22]$, screening for use and associated problems is important. Ecstasy may produce dependence in its own right or, more commonly, independently contribute to a poly-drug dependence syndrome, which has implications for treatment and outcome [70-72].

An issue that clearly requires greater examination in regard to ecstasy dependence is frequency of use. Consistent with earlier findings using DSM criteria [6], while the majority of those classified dependent used ecstasy weekly or more frequently, around $15 \%$ did so much less often, a pattern difficult to reconcile with the loss of control and drug salience features of other stimulant dependence syndromes [73]. There are three key potential explanations for this. Firstly, infrequent users classified as dependent may reflect false-positive classifications or social desirability bias in a survey context. This seems unlikely, however, given the consistency with an earlier study using a structured diagnostic interview [6]. Secondly, the criteria for establishing dependence in the DSM and the SDS cut-off value adapted from amphetamine [54] for this study may be too liberal for application to ecstasy [6]. However, increased rates of harm and problems associated with use were apparent applying this criterion.

Alternatively, frequent use may not be the key contributor to exacerbated harms and psychological dependence; instead it may be the patterns of use that are more germane to this experience. Dependent users were more likely to 'binge' and consume more tablets. There is some ev- idence that these features of use may be related to adverse consequences: in animal models, high doses in binge patterns produce MDMA-induced serotonergic neurotoxicity, while lower doses given on fortnightly schedules do not affect serotonergic function [27, 74]. Humans who binge on ecstasy use more frequently and experience greater social and physical harms [75]. If decreases in functional serotonin produce additional effects exacerbating the neuroadaptive changes that occur following chronic psychoactive substance use, as has been proposed to be the case for the development of ecstasy tolerance [36], then how people consume ecstasy rather than how often may be the important condition for the development of dependence. The relationships are likely to be complex given binge use among non-dependent users and that serotonergic damage varies according to person, environment, purity and coincident polydrug use variables [7680]. Moreover, whether the increased occurrence of binge and higher dosage use are cause or consequence of dependence, can only be evaluated prospectively. However, there is some independent evidence to support this notion, as measures of usage most strongly relating to serotonergic damage (lifetime cumulative dose) have been demonstrated to be superior at differentiating dependent individuals than are measures of recent extent of use [12].

The identification of a bifactorial structure of the SDS items for ecstasy is consistent with earlier findings investigating the structure of DSM-IV dependence items [6], and contrasts with the unifactorial structure identified for both SDS and DSM-IV criteria for methamphetamine and other drugs of dependence $[44,45]$. Given that a bifactorial structure also underlies dependence criteria for hallucinogens [46], this difference in syndrome structure may relate to these drugs' serotonergic actions, in contrast to the stronger dopaminergic effects of methamphetamine and cocaine [81]. One could speculate with respect to the bifactorial structure that the neurobiological changes apparent following chronic administration of other drugs may occur [33], possibly in attenuated form given the antagonistic effects of serotonin activity on dopaminergic release [31], but that other processes involved in the development of dependence are enhanced. Given the unique entactogenic effects of ecstasy/MDMA, there may be a heightened cue reactivity component relating to the behavioural and psychological aspects of ecstasy-related reward [82]. Alternatively, the effects of ecstasy/ MDMA on reducing functional serotonin levels may exacerbate one component of the integrated system involved in drug dependence [81], namely pre-frontal systems mediating behavioural regulation and impulsive- 
ness [83]. In humans, reduced serotonergic activity produces heightened impulsivity on behavioural tasks [84]; increased impulsivity is also apparent in ecstasy consumers relative to controls $[85,86]$, and meta-analyses indicate ecstasy-related deficits in executive function $[2$, 3]. Among some consumers, symptoms of loss of control over use, associated with these cognitive deficits, may be exacerbated, particularly in the presence of cues.

\section{Limitations}

There are three key limitations of this study. Firstly, participants were recruited purposively rather than through random sampling. Sentinel groups of ecstasy users recruited by the same sampling strategies, however, have demonstrated noteworthy representativeness [87]. Secondly, self-report data were not independently verified, for example via biomarkers or collateral interviews. However, such reports demonstrate sufficient reliability and validity for the current context [88]. Finally, while seizure analyses suggest it is likely that ecstasy tablets consumed by the participants contained MDMA $[89,90]$, this cannot be confirmed. However, these inherent constraints also operate when a person presents to treatment services, so the current results clearly have face validity despite these limitations.

\section{Conclusions}

There is clear evidence that some ecstasy consumers do become concerned with their use. The SDS can be employed as a screening tool to identify ecstasy users at higher risk of experiencing adverse consequences, including features of dependence. These findings, consistent with earlier studies [6], do not support the continued classification of ecstasy dependence within the same DSM diagnostic code as amphetamines. Entactogens may instead warrant a unique classification.

\section{Acknowledgements}

The Ecstasy and Related Drugs Reporting System (previously the Party Drugs Initiative) was funded by the Australian Government Department of Health and Aging, the Ministerial Council on Drug Strategy (2005) and the National Drug Law Enforcement Research Fund (2004), and coordinated by the National Drug and Alcohol Research Centre, University of New South Wales. In addition to the authors, the following researchers and research institutions contributed to the data collected for this study: Maria Agaliotis, Courtney Breen, Jennifer Stafford and Bethany White, National Drug and Alcohol Research Centre; Craig Fry, Rebecca Jenkinson, Jennifer Johnston, Anne-Marie Laslett and Mark Stoové, Turning Point Alcohol and Drug Centre Inc.; Robert Ali, David Newcombe, Sophie Pointer, Lynlea Simmonds and Josephine Weekly, Drug and Alcohol Services South Australia; Stuart McLean, University of Tasmania; Francoise Chanteloup, Jessica George and Simon Lenton, National Drug Research Institute; Shelley Cogger, Jane Fischer, Stuart Kinner and Jake Najman, Queensland Alcohol and Drug Research and Education Centre; Kirsten Buckingham, Phoebe Proudfoot, Randolph Sparks, Andrew Staniforth and Jeff Ward, Australian National University; Chris Moon and Jaclyn Newman, Department of Health and Community Services, Northern Territory. We would also like to extend our thanks to the agencies and individuals who assisted with recruitment and interviewing and finally the regular ecstasy users who were willing to be interviewed and share their experience.

\section{References}

1 United Nations Office on Drugs and Crime: World Drug Report 2007. Geneva, United Nations Office on Drugs and Crime, 2008.

-2 Kalechstein AD, De La Garza R, Mahoney JJ, Fantegrossi WE, Newton TF: MDMA use and neurocognition: a meta-analytic review. Psychopharmacology 2007;189:531-537.

-3 Zakzanis KK, Campbell Z, Jovanovski D: The neuropsychology of ecstasy (MDMA) use: a quantitative review. Hum Psychopharmacol 2007;22:427-435.

4 Guillot C: Is recreational ecstasy (MDMA) use associated with higher levels of depressive symptoms? J Psychoactive Drugs 2007; 39:31-39.
5 Falck RS, Wang J, Carlson RG: Depressive symptomatology in young adults with a history of MDMA use: a longitudinal analysis. J Psychopharmacol 2008;22:47-54.

6 Topp L, Hall W, Hando J: Is there a dependence syndrome for ecstasy? National Drug and Alcohol Research Centre Technical Report No 51. Sydney, NDARC, 1997.

7 Jansen KLR: Ecstasy (MDMA) dependence. Drug Alcohol Depend 1999;53:121-124.

8 Cottler LB, Womack SB, Compton WM, Ben-Abdallah A: Ecstasy abuse and dependence among adolescents and young adults: applicability and reliability of DSM-IV criteria. Hum Psychopharmacol Clin Exp 2001; 16:599-606.
-9 Von Sydow K, Lieb R, Pfister H, Höfler M, Wittchen H-U: Use, abuse and dependence of ecstasy and related drugs in adolescents and young adults - a transient phenomenon? Results from a longitudinal community study. Drug Alcohol Depend 2002;66:147159.

10 Yacoubian GS, Peters RJ, Palacios WR, Link TC: Identifying the perceived and diagnosed prevalence of ecstasy dependence among club rave attendees: J Ethnicity Subst Abuse 2004;3:33-45.

11 Yen C, Hsu S: Symptoms of ecstasy dependence and correlation with psychopathology in Taiwanese adolescents. J Nerv Ment Dis 2007; 195:866-869. 
12 Scheier L, Abdullah A, Inciardi J, Copeland J, Cottler L: Tri-city study of Ecstasy use problems: a latent class analysis. Drug Alcohol Depend 2008;98:249-263.

13 Abdallah A, Scheier L, Inciardi J, Copeland J, Cottler L: A psycho-economic model of ecstasy consumption and related consequences: a multi-site study with community samples. Subst Use Misuse 2007;42:1651-1684.

14 Milani M: The nature of ecstasy dependence. Abstract presented at the Psychobiology of MDMA or Ecstasy International Conference, Victoria, 11-12 September 2008.

15 Shuglin AT: The background and chemistry of MDMA. J Psychoactive Drugs 1986;18: 291-304.

$\checkmark 16$ Solowij N, Hall W, Lee N: Recreational MDMA use in Sydney: a profile of 'ecstasy' users and their experiences with the drug. $\mathrm{Br}$ J Addict 1992;87:1161-1172.

17 Winstock AR, Griffiths P, Stewart D: Drugs and the dance music scene: a survey of current drug use patterns among a sample of dance music enthusiasts in the UK. Drug Alcohol Depend 2001;64:9-17.

18 Black E, Dunn M, Degenhardt L, Campbell G, George J, Kinner S, Matthews A, Quinn B, Roxburgh A, Urbancic-Kenny A, White N: Australian Trends in Ecstasy and Related Drug Markets 2007: Findings from the Ecstasy and Related Drugs Reporting System. Australian Drug Trends Series No 10. Sydney, National Drug and Alcohol Research Centre, 2008.

19 Verheyden SL, Henry JA, Curran HV: Acute, subacute and long-term subjective consequences of 'ecstasy' (MDMA) consumption in 430 regular users. Hum Psychopharmacol Clin Exp 2003;18:507-517.

-20 Leung K, Li J, Tsay W, Callahan C, Liu S, Hsu J, Hoffer L, Cottler L: Dinosaur girls, candy girls and Trinity: voices of Taiwanese club drug users. J Ethn Subst Abuse 2008;7:237257.

21 Substance Abuse and Mental Health Services Administration: Treatment Episode Data Set (TEDS). Highlights - 2006. National Admissions to Substance Abuse Treatment Services, DASIS Series: S 40, Rockville, 2008.

22 Australian Institute of Health and Welfare: Alcohol and other drug treatment services in Australia 2005-2006: report on the National Minimum Data Set. Drug Treatment Series No 7, cat No HSE 53. Canberra, AIHW, 2007.

-23 Schifano F: Potential human neurotoxicity of MDMA ('Ecstasy'): subjective self-reports, evidence from an Italian drug addiction centre and clinical case studies. Neuropsychobiology 2000;42:25-33.

24 Maxwell JC, Spence RT: Profiles of club drug users in treatment. Subst Use Misuse 2005; 40:1409-1426.

-25 Hopfer C, Mendelson B, Van Leeuwen JM, Kelly S, Hooks S: Club drug use among youths in treatment for substance abuse. Am J Addict 2006;15:94-99.
26 Trigo JE, Panayi F, Soria G, Maldonado R, Robeldo P: A reliable model of intravenous MDMA self-administration in naïve mice. Psychopharmacology 2006;184:212-220.

27 Fantegrossi WE: Reinforcing effects of methylenedioxymethamphetamine congeners in rhesus monkeys: are intravenous self-administration experiments relevant to MDMA neurotoxicity? Psychopharmacology 2007; 189:471-482.

28 Robeldo P, Balerio G, Berrendero F, Maldonado R: Study of the behavioural responses related to the potential addictive properties of MDMA in mice. Naunyn-Schmiedeberg's Arch Pharmacol 2004;369:338-349.

29 Daza-Losada M, Do Couto BR, Manzanedo C, Aguilar MA, Rodriguez-Arias M, Minarro J: Rewarding effects and reinstatement of MDMA-induced CPP in adolescent mice. Neuropsychopharmacology 2007;32:1750 1759

30 Daniela E, Gittings D, Schenck S: Conditioning following repeated exposure to MDMA in rats: role in the maintenance of MDMA self-administration. Behav Neurosci 2006; 120:1144-1150.

31 Bankson MG, Yamamoto BK: SerotoninGABA interactions modulate MDMA-induced mesolimbic dopamine release. J Neurochem 2004;91:852-859.

32 Robeldo P, Mendizabai V, Ortuno J, de la Torre R, Kieffer BL, Maldonado R: The rewarding properties of MDMA are preserved in mice lacking $\mu$-opioid receptors. Eur J Neurosci 2004;20:853-858.

33 Koob GF: The neurobiology of addiction: a neuroadaptational view relevant for diagnosis. Addiction 2006;101(suppl 1):23-30.

34 Lile JA, Ross JT, Nader MA: A comparison of the reinforcing efficacy of 3,4-methylenedioxymethamphetamine (MDMA, 'ecstasy') with cocaine in rhesus monkeys. Drug Alcohol Depend 2005;78:135-140.

35 Wang Z, Woolverton WL: Estimating the relative reinforcing strengths of ( \pm )-3,4-methylenedioxymethamphetamine (MDMA) and its isomers in rhesus monkeys: comparison to (+)-methamphetamine. Psychopharmacology 2007;189:483-488.

36 Parrott AC: Chronic tolerance to recreational MDMA (3,4-methylenedioxymethamphetamine) or ecstasy. J Psychopharmacol 2005;19:71-83.

37 Gawin FH, Kleber HD: Abstinence symptomatology and psychiatric diagnosis in cocaine abusers: clinical observations. Arch Gen Psychiatry 1986;43:107-113.

38 Curran HV, Travill RA: Mood and cognitive effects of \pm -3,4-methylenedioxymethamphetamine (MDMA, 'ecstasy'): week-end 'high' followed by mid-week low. Addiction 1997;92:821-831.

-39 Green AR, Mechan AO, Elliott JM, O’Shea E, Colado MI: The pharmacology and clinical pharmacology of 3,4-methylenedioxymethamphetamine (MDMA, 'Ecstasy'). Pharmacol Rev 2003;55:463-508.
40 Parrott A, Lasky J: Ecstasy (MDMA) effects upon mood and cognition: before, during and after a Saturday night dance. Psychopharmacology 1998;139:261-268.

41 Edwards G, Gross M: Alcohol dependence: provisional description of a clinical syndrome. Br Med J 1976;6107:1058-1061.

42 American Psychiatric Association: Diagnostic and Statistical Manual of Mental Disorders, ed 4, rev. Arlington, American Psychiatric Association, 2000.

43 Quinn C, Breen C, White B: Illicit tablet market in Victoria. Party Drug Trends Bulletin, June 2004. Sydney, National Drug and Alcohol Research Centre, University of New South Wales, 2004

44 Topp L, Darke S: The applicability of the dependence syndrome to amphetamine. Drug Alcohol Depend 1997;48:113-118.

-45 Nelson CB, Rehm J, Üstün TB, Grant B, Chatterji S: Factor structures for DSM-IV substance disorder criteria endorsed by alcohol, cannabis, cocaine and opiate users: results from the WHO reliability and validity study. Addiction 1999;94:843-855.

46 Morgenstern J, Langenbucher J, Labouvie EW: The generalisability of the dependence syndrome across substances: an examination of some properties of the proposed DSM-IV dependence criteria. Addiction 1994;89:1105-1115

-47 Hasin D, Hatzenbuehler ML, Keyes K, Ogburn E: Substance use disorder: Diagnostic and Statistical Manual of Mental Disorders, fourth edition (DSM-IV) and International Classification of Diseases, tenth edition (ICD-10). Addiction 2006;101(suppl 1):5975.

48 Nestler EJ: Is there a common molecular pathway for addiction? Nat Neurosci 2005;8: 1445-1449.

49 Schuckit MA, Saunders JB: The empirical basis of substance use disorders diagnosis: research recommendations for the Diagnostic and Statistical Manual of Mental Disorders, fifth edition (DSM-V). Addiction 2006; 101(suppl 1):170-173

50 Edwards G, Arif A, Hodgston R: Nomenclature and classification of drug- and alcoholrelated problems: a shortened version of a WHO memorandum. Drug Alcohol Rev 1984;3:76-85.

51 Gossop M, Darke S, Griffiths P, Hando J, Powis B, Hall W, Strang J: The Severity of Dependence Scale (SDS): psychometric properties of the SDS in English and Australian samples of heroin, cocaine and amphetamine users. Addiction 1995;90:607-614.

52 Gossop M, Best D, Marsden J, Strang J: Testretest reliability of the Severity of Dependence Scale. Addiction 1997;92:353-354.

-53 Kaye S, Darke S: Determining a diagnostic cut-off on the Severity of Dependence Scale (SDS) for cocaine dependence. Addiction 2002;97:727-731 
54 Topp L, Mattick RP: Choosing a cut-off on the Severity of Dependence Scale (SDS) for amphetamine users. Addiction 1997;92: $839-845$.

55 Swift W, Copeland J, Hall W: Choosing a diagnostic cut-off for cannabis dependence. Addiction 1998;93:1681-1692.

-56 De las Cuevas C, Sanz EJ, de la Fuente JA, Padilla J, Berenguer JC: The Severity of Dependence Scale (SDS) as screening test for benzodiazepine dependence: SDS validation study. Addiction 2000;95:245-250.

57 Leung K, Cottler L: Ecstasy and other club drugs: a review of recent epidemiologic studies. Curr Opin Psychiatry 2008;21:234-241.

-58 Topp L, Breen C, Kaye S, Darke S: Adapting the Illicit Drug Reporting System (IDRS) methodology to examine the feasibility of monitoring trends in party drug markets. Drug Alcohol Depend 2004;73:189-197.

59 Stafford J, Degenhardt L, Dunn M, Fischer J, George J, Johnston J, Matthews A, Newman J, Proudfoot P, Weekly J: Australian trends in Ecstasy and related drug markets 2005: findings from the Party Drugs Initiative (PDI). National Drug and Alcohol Research Centre Monograph No 58. Sydney, NDARC, 2006.

60 Dunn M, Degenhardt L, Campbell G, George J, Johnston J, Kinner S, Mathews A, Newman J, White N: Australian trends in Ecstasy and related drug markets 2006: findings from the Ecstasy and Related Drugs Reporting System (EDRS). National Drug and Alcohol Research Centre Monograph No 61. Sydney, NDARC, 2007.

61 Steiger JH: Structural model evaluation and modification: an interval estimation approach. Multivar Behav Res 1990;25:173180.

62 Bentler PM: Comparative fit indexes in structure models. Psychol Bull 1990;107: 238-246.

63 Marsh HW, Hau KT, Wen ZL: In search of golden rules: comment on hypothesis testing approaches to setting cutoff values for fit indexes and dangers in overgeneralizing $\mathrm{Hu}$ and Bentler's 1999 findings. Struct Equation Modelling 2004;11:320-341.

64 Yuan KH: Fit indices versus test statistics. Multivar Behav Res 2005;40:115-148.

-65 Barrett P: Structural equation modelling: adjudging model fit. Pers Indiv Diff 2007;42: 815-824.

$66 \mathrm{Hu}$ L, Bentler P: Cutoff criteria for fit indexes in covariance structure analysis: conventional criteria versus new alternatives. Struct Equation Modelling 1999;6:1-55.
67 Mulaik S: There is a place for approximate fit in structural equation modelling. Pers Indiv Diff 2007;42:883-891.

68 Steiger JH: Understanding the limitations of global fit assessment in structural equation modelling. Pers Indiv Diff 2007;42:893898.

69 Bruno R, Matthews A: Psychometric characteristics of the Severity of Dependence Scale for methamphetamine and 'ecstasy'. Paper presented at the 2006 Australasian Professional Society on Alcohol and Other Drugs Conference, Cairns, 2006.

70 Gunter TT, Arndt S, Wenman G: Characteristics of admissions for primary stimulant dependence during 2001. Subst Use Misuse 2006;41:1277-1286.

71 Darke S, Ross J: Polydrug dependence and psychiatric comorbidity among heroin injectors. Drug Alcohol Depend 1997;48:135141.

72 Ciraulo DA, Piechniczek-Buczek J, Iscan EN: Outcome predictors in substance use disorders. Psychiatr Clin North Am 2003;26:381409.

73 Topp L, Mattick RP: Validation of the amphetamine dependence syndrome and the SAmDQ. Addiction 1997;92:151-162.

74 De La Garza R, Fabrizio KR, Gupta A: Relevance of rodent models of intravenous MDMA self-administration to human MDMA consumption patterns. Psychopharmacology 2007; 189:425-434.

75 Topp L, Hando J, Dillon P, Roche A, Solowij N: Ecstasy use in Australia: patterns of use and associated harm. Drug Alcohol Depend 1999;55:105-115.

76 Parrott AC: MDMA (3,4-methylenedioxymethamphetamine) or ecstasy: the neuropsychobiological implications of taking it at dances and raves. Neuropsychobiology 2004; 50:329-335

77 Parrott AC, Rodgers J, Buchanan T, Ling J, Heffernan T, Scholey AB: Dancing hot on ecstasy: physical activity and thermal comfort ratings are associated with the memory and other psychobiological problems reported by recreational MDMA users. Hum Psychopharmacol 2006;21:285-298.

78 Soar K, Turner JJ, Parrott AC: Problematic vs. non-problematic ecstasy/MDMA use: the influence of drug usage patterns and pre-existing psychiatric factors. J Psychopharmacol 2006;20:417-424.
79 Parrott AC: MDMA in humans: factors which affect the neuropsychobiological profiles of recreational ecstasy users, the integrative role of bioenergetic stress. J Psychopharmacol 2006;20:147-163.

80 Parrott AC, Milani RM, Gouzoulis-Mayfrank E, Daumann J: Cannabis and ecstasy/ MDMA (3,4-methylenedioxymethamphetamine): an analysis of their neuropsychobiological interactions in recreational users. J Neural Transm 2007;114:959-968.

81 Koob GF, le Moal M: Neurobiology of Addiction. London, Elsevier, 2006.

82 West R: Theory of Addiction. Oxford, Blackwell Publishing, 2006.

83 Yucel M, Lubman DI: Neurocognitive and neuroimaging evidence of behavioural dysregulation in human drug addiction: implications for diagnosis, treatment and prevention. Drug Alcohol Rev 2007;26:33-39.

$>84$ Cools R, Blackwell A, Clark L, Menziea L, Cox S, Robins TW: Tryptophan depletion disrupts the motivational guidance of goaldirected behaviour as a function of trait impulsivity. Neuropsychopharmacology 2005; 30:1362-1373.

85 Morgan MJ, Impallomeni LC, Pirona A, Rogers RD: Elevated impulsivity and impaired decision-making in abstinent ecstasy (MDMA) users compared to polydrug and drug-naive controls. Neuropsychopharmacology 2006;31:1562-1573.

86 Quednow BB, Kuhn K, Hoppe C, Westheide J, Maier W, Daum I, Wagner M: Elevated impulsivity and impaired decision-making cognition in heavy users of MDMA ('ecstasy'). Psychopharmacology 2007; 198:517530.

87 Topp L, Barker B, Degenhardt L: The external validity of results derived from ecstasy users recruited using purposive sampling strategies. Drug Alcohol Depend 2004;73: 33-40.

88 Darke S: Self-report among injecting drug users: a review. Drug Alcohol Depend 1998; 51:253-263.

89 Quinn C, Dunn M, Degenhardt L: The illicit tablet market in Victoria, 2004-2007. EDRS Drug Trends Bulletin, December 2007. Sydney, National Drug and Alcohol Research Centre, University of New South Wales, 2007.

90 Parrott AC: Is ecstasy MDMA? A review of the proportion of ecstasy tablets containing MDMA, their dosage levels, and the changing perceptions of purity. Psychopharmacology 2004; 173:234-241. 